J. Lake Sci. (湖泊科学), 2006, 18(5):545-549

http:// www. jlakes. org. E-mail: jlakes@ niglas. ac.cn

(c) 2006 by Journal of Lake Sciences

\title{
鄱阳湖乐安河流域水质监测优化布点"
}

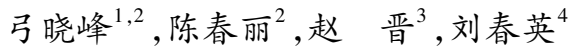

( 1 : 南昌大学教育部鄱阳湖湖泊生态与生物资源利用实验室, 南昌 330047)

( 2 : 南昌大学环境科学与工程学院, 南昌 330029)

(3: 南昌有色冶金设计研究院, 南昌 330002)

( 4 : 江西财经大学环境与资源学院,南昌 330013 )

摘 要: 采用鄱阳湖乐安河流域 13 个监测断面 $1995-2002$ 年 8 年的污染指标的监测平均值作为原始数据, 应用物元分析 法对各监测断面进行优化. 在确定最佳和最次理想点的基础上,建立标准物元矩阵和节域物元矩阵,并结合综合关联函 数, 选出优化点位. 同时应用相关分析中的距离分析和 $K-$ 均值聚类法确定各监测点所属类别. 综合这三种优化结果, 最 终确定乐安河流域可以由传统的 13 个监测点位优化为 9 个监测点位.

关键词:乐安河;优化布点;物元分析;相关分析;聚类法

\section{Optimized points selection of the water quality monitoring in the Le' an River Basin of} Lake Poyang

GONG Xiaofeng ${ }^{1,2}$, CHEN Chunli ${ }^{2}$, ZHAO Jin ${ }^{3} \&$ LIU Chunying ${ }^{4}$

(1: Key Laboratory of Lake Poyang Ecology and Bio-resource Utilization of MOE, Nanchang University, Nanchang 330047 ,P. R. China)

(2: School of Environmental Science and Engineering of Nanchang University, Nanchang 330029, P. R. China)

(3: Nanchang Engineering and Reserch institute of Nonferrous Metals, Nanchang 330002, P. R. China)

(4:School of Environmental and Resource of Jiangxi Financial University, Nanchang 330013, P. R. China)

Abstract: The matter element analysis has been used to optimize points selection of water quality monitoring in the Leán River basin of Lake Poyang, taking the average monitoring data in 8 years which is from 1995 to 2002 as the original data. Matter element matrix of standard and partial unit can be established on condition that optimum and second optimum points are chosen, connected with integrative and correlative function, the optimized points are chosen. Meanwhile, the distances method which is belonged to the correlation and the $K$-Means Cluster process are used to the classification of monitoring points. Integrating three methods above, the 13 traditional monitoring points in the Le' an River basin of Lake Poyang can be optimized to 9 monitoring sites.

Keywords: Le' an River; optimized points selection; matter element analysis; correlation; $K$-Means Cluster

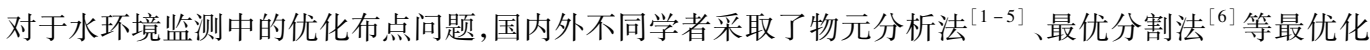
布点方法. 物元分析法 ${ }^{[7]}$ 是处理不相容问题的一种有效方法, 将其运用在对大气、噪声以及水质监测布点 的优化上, 可取得令人满意的结果. 本文采用物元分析法对乐安河流域监测断面进行优化, 同时应用相关分 析和 $\mathrm{K}$ - 均值聚类法确定各监测点所属类别, 得到最优化水质监测断面, 目前尚未见相关文献报道.

\section{1 乐安河监测点位状况}

乐安河源于江西与浙江省交界处,流经娿源、德兴、乐平、万年、鄱阳等县 (市), 在鄱阳以南约 $10 \mathrm{~km}$ 处

* 教育部科学技术研究重点项目 (204076) 和江西省教育厅科学技术项目联合资助. 2005-10-19 收稿;2005-1219 收修改稿. 弓晓峰,女, 1962 年生, 博士, 教授; E-mail :xfgong@ ncu. edu. cn. 
的姚公渡与昌江汇成饶河后进人鄱阳湖, 全长 $279 \mathrm{~km}$. 中国最大的露天开采铜矿一德兴铜矿位于乐安河上 游, 再加上沿岸工业废水、生活污水等污染, 致使乐安河多项污染物指标超标, 尤其是 $\mathrm{Cu} 、 \mathrm{~Pb} 、 \mathrm{COD}_{\mathrm{Cr}}$ 、氨氮等 严重超标, 其污染已经波及到鄱阳湖的水质 ${ }^{[8-13]}$.

乐安河流域传统监测布点示意图及各监测断面设置状况分别见图 1 和表 1 所示.

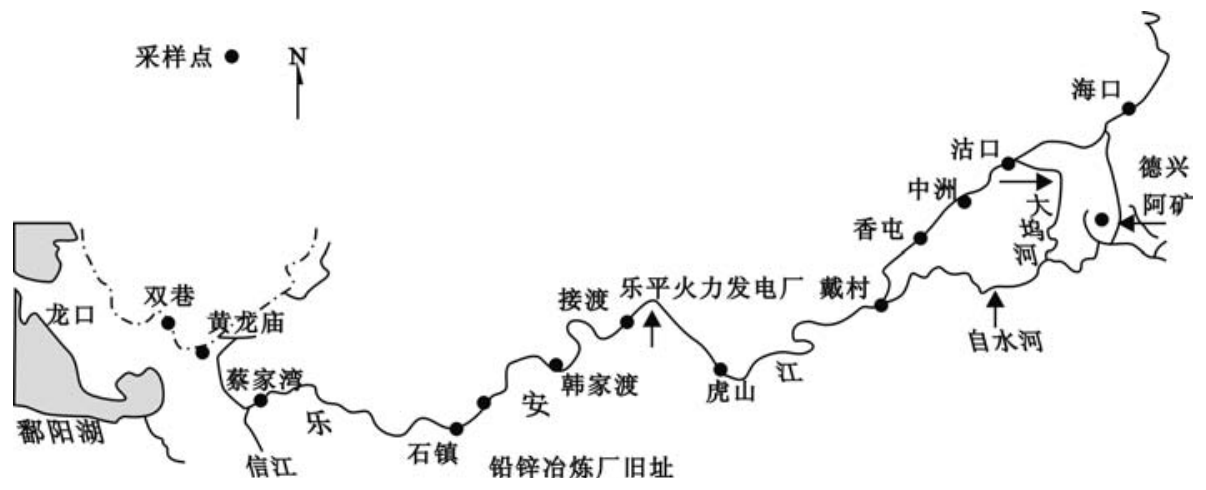

图 1 乐安河流域监测布点点位图

Fig. 1 monitoring points in the Le' an River basin of Lake Poyang

表 1 乐安河流域水质现状调查站位表

Tab. 1 Survey sites of the water quality status in quo

\begin{tabular}{|c|c|c|c|c|c|}
\hline 序号 & 断面名称 & 设置目的 & 水质类别 & 水质目标 & 备注 \\
\hline $\mathrm{A} 1$ & 海口 & 对照站位 & III & III & 省控断面 \\
\hline $\mathrm{A} 2$ & 沽口 & 大坞河乐安河汇合口 & 劣 V & $\mathrm{IV}$ & 建议断面 \\
\hline A3 & 中洲 & 乐安河上游监控断面 & IV & III & 省控断面 \\
\hline A4 & 香屯 & & III & III & 省控断面 \\
\hline A5 & 戴村 & 洎水河与乐安河交汇处 & III & III & 省控断面 \\
\hline A6 & 虎山 & 有一历史较长的水文观测站 & II & II & 市控断面 \\
\hline A7 & 接渡 & 原有一火力发电厂、排放污染物 & III & III & 建议断面 \\
\hline A8 & 韩家渡 & 乐平城市废水及乐安河上游污染物的汇合口 & III & III & 省控断面 \\
\hline A9 & 镇桥 & & III & III & 建议断面 \\
\hline A10 & 石镇 & 曾有一有色冶炼厂 & III & III & 建议断面 \\
\hline A11 & 蔡家湾 & 位于波阳县, 该段河流弯度大, 河面宽, 水量大 & III & III & 建议断面 \\
\hline $\mathrm{A} 12$ & 双港 & 乐安河下游监控断面 & III & III & 建议断面 \\
\hline A13 & 龙口 & 乐安河人鄱阳湖口 & III & III & 建议断面 \\
\hline
\end{tabular}

\section{2 物元分析与结果}

\section{1 标准物元矩阵和节域物元矩阵的建立}

以乐安河流域各监测断面 $1995-2002$ 年 8 年来几项污染指标平均值作原始数据 (表 2 ) 进行物元分 析. 根据物元分析法及水质监测优化布点原理 ${ }^{[2,5,7]}$, 结合表 2 中 $a 、 b 、 c$ 各项污染指标值, 分别建立标准物 元矩阵和节域物元矩阵. 将每个采样点作为一个事物, 其污染指标测定值构成一个待优化的物元矩阵.

\section{2 关联函数的计算}

2.2 .1 线性关联函数的计算 监测点位的各单项指标对 “最佳” “最次” 理想标准的线性关联函数公式为: 


$$
\begin{aligned}
& K_{a}\left(X_{i j}\right)=\frac{X_{i j}-c_{j}}{c_{j}-a_{j}} \\
& K_{b}\left(X_{i j}\right)=\frac{X_{i j}-c_{j}}{c_{j}-b_{j}}
\end{aligned}
$$

式中, $X_{i j}$ 为采样点第 $j$ 项污染指标监测值, $a_{j} b_{j} c_{j}$ 分别为最佳理想点 $a$ 、最次理想点 $b$ 及数学期望点 $c$ 的第 $j$ 项污染指标值. 将表 2 数据代人 (1)、(2) 式, 得各采样点单项指标线性关联函数.

2.2.2 综合关联函数的计算 4 项污染指标的综合关联函数为:

$$
\begin{aligned}
& K_{a}\left(X_{i}\right)=\sum_{j=1}^{4} W_{j} K_{a}\left(X_{i j}\right) \\
& K_{b}\left(X_{i}\right)=\sum_{j=1}^{4} W_{j} K_{b}\left(X_{i j}\right)
\end{aligned}
$$

式中, $W_{j}$ 为第 $j$ 项污染指标的权值. 按以上公式、地面水环境质量标准 ${ }^{[14]}$ 和权值计算各监测点的综合关联 函数 $K_{a}\left(X_{i}\right)$ 及 $K_{b}\left(X_{i}\right)$ 值, 结果如表 3 .

表 $21995-2002$ 年枯水期乐安河水质检测平均值统计结果

Tab. 2 Mean statistical results of the water quality of Le' an River in low-water period from 1995 to 2002

\begin{tabular}{cccccc}
\hline 序号 & 段面名称 & $\mathrm{COD}_{\mathrm{Cr}}(\mathrm{mg} / \mathrm{L})$ & 氨氮 $(\mathrm{mg} / \mathrm{L})$ & 总铜 $(\mathrm{mg} / \mathrm{L})$ & 总铅 $(\mathrm{mg} / \mathrm{L})$ \\
\hline $\mathrm{A} 1$ & 海口 & 17.65 & 0.32 & $<0.002$ & 未检出 \\
$\mathrm{A} 2$ & 沽口 & 32.31 & 0.30 & 3.387 & 0.005 \\
$\mathrm{~A} 3$ & 中洲 & 25.92 & 0.32 & 0.827 & 0.011 \\
$\mathrm{~A} 4$ & 香屯 & 26.93 & 0.29 & 0.968 & 0.005 \\
$\mathrm{~A} 5$ & 戴村 & 22.69 & 0.24 & 0.217 & 0.029 \\
$\mathrm{~A} 6$ & 虎山 & 19.36 & 0.26 & 0.138 & 0.208 \\
$\mathrm{~A} 7$ & 接渡 & 20.31 & 0.43 & 0.132 & 0.034 \\
$\mathrm{~A} 8$ & 韩家渡 & 21.32 & 0.45 & 0.246 & 0.020 \\
$\mathrm{~A} 9$ & 镇桥 & 21.12 & 1.20 & 0.153 & 0.109 \\
$\mathrm{~A} 10$ & 石镇 & 19.61 & 1.02 & 0.162 & 0.005 \\
$\mathrm{~A} 11$ & 蔡家湾 & 22.78 & 0.46 & 0.116 & 0.142 \\
$\mathrm{~A} 12$ & 双巷 & 23.34 & 0.32 & 0.108 & 0.093 \\
$\mathrm{~A} 13$ & 龙口 & 13.89 & 0.41 & 0.105 & 未检出 \\
& 最佳理想点 $\mathrm{a}$ & 13.89 & 0.24 & 0.105 & 0 \\
& 最次理想点 $\mathrm{b}$ & 32.31 & 1.20 & 3.387 & 0.208 \\
& 数学期望点 $\mathrm{c}$ & 22.09 & 0.46 & 0.505 & 0.051 \\
\hline
\end{tabular}

表 3 综合关联函数

Tab. 3 Integrative and correlative function

\begin{tabular}{cccccccc}
\hline 序号 & 断面名称 & $K_{a}\left(X_{i}\right)$ & $K_{b}\left(X_{i}\right)$ & 序号 & 断面名称 & $K_{a}\left(X_{i}\right)$ & $K_{b}\left(X_{i}\right)$ \\
\hline $\mathrm{A} 1$ & 海口 & 0.152 & -0.246 & $\mathrm{~A} 8$ & 韩家渡 & 0.115 & -0.388 \\
$\mathrm{~A} 2$ & 沽口 & -0.351 & 1.367 & $\mathrm{~A} 9$ & 镇桥 & -0.224 & 0.681 \\
$\mathrm{~A} 3$ & 中洲 & -0.01 & -0.083 & $\mathrm{~A} 10$ & 石镇 & 0.097 & -0.237 \\
$\mathrm{~A} 4$ & 香屯 & -0.029 & -0.039 & $\mathrm{~A} 11$ & 蔡家湾 & -0.207 & 0.49 \\
$\mathrm{~A} 5$ & 戴村 & 0.096 & -0.422 & $\mathrm{~A} 12$ & 双巷 & -0.08 & 0.061 \\
$\mathrm{~A} 6$ & 虎山 & -0.229 & 0.732 & $\mathrm{~A} 13$ & 龙口 & 0.27 & -0.522 \\
$\mathrm{~A} 7$ & 接渡 & 0.122 & -0.392 & & & & \\
\hline
\end{tabular}

\section{3 结果分析}

根据关联函数含义, 并结合各采样点在图 2 中 $K a-K b$ 平面上的点聚图分布情况, 将 13 个监测断面优 


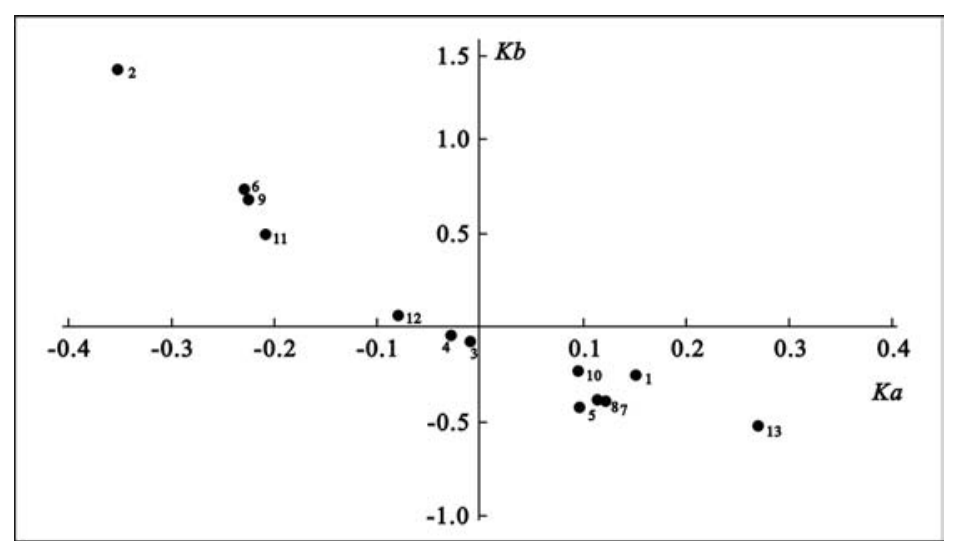

图 $2 K_{a}$ 和 $K_{b}$ 图

Fig. $2 K_{a}$ and $K_{b}$

化为 10 个监测断面. $\mathrm{A} 2$ 为一类; $\mathrm{A} 6 、 \mathrm{~A} 9$ 可优化为同一类; $\mathrm{A} 11$ 号为一类; $\mathrm{A} 12$ 为一类; $\mathrm{A} 5$ 为一类; $\mathrm{A} 7 、 \mathrm{~A} 8$ 为 一类; $\mathrm{A} 10$ 为一类; $\mathrm{A} 1$ 为一类, $\mathrm{A} 13$ 为一类; $\mathrm{A} 3 、 \mathrm{~A} 4$ 为另外一类. 分布在第 II 象限的监测断面符合 “最佳理想 标准” 点位条件, 而 $A 2 、 A 6 、 A 11 、 A 12$ 符合程度最好, 故 $A 2 、 A 6 、 A 11 、 A 12$ 为最优选监测断面; 分布在第 $I V$ 象 限内的监测断面符合 “最次理想标准” 点位条件, A1、A5、A8、A10、A13 监测断面符合程度最好, 故 A1、A5、 A8、A10、A13 监测断面为另一类优选断面. A3、A4 分布在 III 象限,不符合 “最佳理想标准” 和“最次理想标 准” 条件, 但考虑其位于乐安河上游, 且香屯设有水文站,故把 A3 和 A4 优化为一个监测断面,作为乐安河 的上游监控断面,因 A4 比 A3 符合程度稍好,故选择 A4.

由上所述,用物元分析法可把乐安河流域优化为以下 10 个监测断面: $\mathrm{A} 1 、 \mathrm{~A} 2 、 \mathrm{~A} 4 、 \mathrm{~A} 5 、 \mathrm{~A} 6 、 \mathrm{~A} 8 、 \mathrm{~A} 10 、 \mathrm{~A} 11$ 、 $\mathrm{A} 12 、 \mathrm{~A} 13$, 即海口、沽口、香屯、戴村、虎山、韩家渡、石镇、蔡家湾、双巷和龙口.

\section{3 相关性分析 ${ }^{[15]}$}

相关分析中的距离分析就是通过距离长短来判别变量之间的相似性,把彼此距离较近的归为一类, 通 常用于变量的分类. 利用 SPSS 软件中的距离分析对上述 13 个监测点位进行分析, 以两变量差值平方和的 平方根为各点位间的距离, 从距离上看, A3 和 A4 间距离约为 1, 故把 A3 和 A4 归为一类; A5 和 A12 间距离 小于 1 , 归为一类; $\mathrm{A} 6, \mathrm{~A} 7, \mathrm{~A} 11$ 相互间距离小于 1 , 归为一类; $\mathrm{A} 8, \mathrm{~A} 9, \mathrm{~A} 10$ 相互间距离小于 1 , 归为一类; $\mathrm{A} 1, \mathrm{~A} 2, \mathrm{~A} 13$ 各自一类.

故由两变量差值平方和的平方根距离, 把 13 个监测点分为以下 7 类: $A 1$ 为一类, $A 2$ 为一类, $A 3 、 A 4$ 为 一类, $\mathrm{A} 5 、 \mathrm{~A} 12$ 为一类, $\mathrm{A} 6 、 \mathrm{~A} 7 、 \mathrm{~A} 11$ 为一类, $\mathrm{A} 8 、 \mathrm{~A} 9 、 \mathrm{~A} 10$ 为一类, $\mathrm{A} 13$ 为一类.

\section{$\mathbf{4} \boldsymbol{K}-$ 均值聚类法结果与分析 $^{[15]}$}

$K$-均值聚类分析可以确定各样点属性,采用 SPSS 软件中的 $K-$ 均值聚类法过程对表 2 数据进行处 理, 得到快速聚类分析观测量所属类表, 它把所有监测点位分为四大类. A1 号和 A13 号属于同一类; A3 号 和 A4 号为一类; A2 号独自一类; 而其余各监测点为另一类. 结合其得到的快速聚类分析最终类中心间距离 表来看, 说明第一和第二类、第一和第四类、第二和第三类距离较远,其余各类之间距离相对小一些. 同时, 第三类同类之间距离也存在一定差异,故第三类还需细分. 在考虑优化必须设有主要监测断面、控制断面和 对照断面的原则上,把 A1 号和 A13 号划为两类.

\section{5 结论}

三种方法优化结果比较见表 4 . 
表 4 几种方法优化结果比较

Tab. 4 The comparation of the optimized results of the three method

\begin{tabular}{cccc}
\hline 所属类别 & 物元分析法 & 相关分析 & $K-$ 均值聚类法 \\
\hline 第一类 & $\mathrm{A} 1$ & $\mathrm{~A} 1$ & $\mathrm{~A} 1 、 \mathrm{~A} 13$ \\
第二类 & $\mathrm{A} 2$ & $\mathrm{~A} 2$ & $\mathrm{~A} 2$ \\
第三类 & $\mathrm{A} 3 、 \mathrm{~A} 4$ & $\mathrm{~A} 3 、 \mathrm{~A} 4$ & $\mathrm{~A} 3 、 \mathrm{~A} 4$ \\
第四类 & $\mathrm{A} 5$ & $\mathrm{~A} 5 、 \mathrm{~A} 12$ & 其余为一类 \\
第五类 & $\mathrm{A} 6 、 \mathrm{~A} 9$ & $\mathrm{~A} 6 、 \mathrm{~A} 7 、 \mathrm{~A} 11$ & \\
第六类 & $\mathrm{A} 7 、 \mathrm{~A} 8$ & $\mathrm{~A} 8 、 \mathrm{~A} 9 、 \mathrm{~A} 10$ & \\
第七类 & $\mathrm{A} 10$ & & \\
第八类 & $\mathrm{A} 11$ & & \\
第九类 & $\mathrm{A} 12$ & $\mathrm{~A} 13$ & \\
第十类 & $\mathrm{A} 13$ & &
\end{tabular}

从以上分析可知:

(1) 运用物元分析法进行监测断面得优化布点过程中, 其物元理论通俗易懂, 计算简便, 也容易进行计 算机编程,并且物元分析结果显而易见.

(2) 用 K - 均值聚类法并借助 SPSS 软件可以很容易得到各监测点位所属类别, 但其类别太过于笼统, 需要进一步细分; 再结合相关分析, 综合这三种方法来对监测点位进行优化布点, 结果更理想, 更切合实际, 弥补了单一方法所存在的客观缺陷.

综合三种方法的优化结果, 并结合乐安河目前的传统采样点布设情况, 可以把乐安河各监测点位优化 为 $\mathrm{A} 1, \mathrm{~A} 2, \mathrm{~A} 4, \mathrm{~A} 5, \mathrm{~A} 6, \mathrm{~A} 8, \mathrm{~A} 10, \mathrm{~A} 11, \mathrm{~A} 13$, 即海口、沽口、香屯、戴村、虎山、韩家渡、石镇、蔡家湾和龙口, 共 9 个断面. 可以准确代表测区的实际情况; 同时也提高了监测数据的有效性和代表性,并避免了重复设置带来 的经济投人过大,减少了一定的工作量和经费.

\section{6 参考文献}

１１］国家环境保护局. 环境监测技术规范(第一册). 北京: 中国环境科学出版社, 1986:2-10.

[2] 高明慧. 用物元分析进行水质环境监测优化布点的研究. 环境科学进展, 1997,5(3): $77-81$.

[3] 高明慧. 物元分析在水质富营养化评价中的应用. 环境科学进展, 1995,3(5):43-49.

[4] 高明慧.物元分析在大气环境质量综合评价中的应用. 环境监测技术与管理, 1996,8 (3):22-24.

５］张 勇, 黄醒群, 易志伟等. 灰色局势物元分析进行河流优化布点. 中国环境监测, 1999,15(3):24 -26 .

[6] 张青新.最优分割法在河流断面优化中的应用. 环境科技, 1991,11(6):28-31.

[7] 蔡 文.物元分析. 广州:广东高等教育出版社, 1987.

[8] 简敏菲,弓晓峰,游 海等. 鄱阳湖水土环境及其水生维管束植物重金属污染. 长江流域资源与环境, $2004, \mathbf{1 3}(6): 589-593$.

[9] 简敏菲, 弓晓峰,游 海等. 水生植物对铜、铅、锌等重金属元素富集作用的评价研究. 南昌大学学报, $2004,26(1): 85-88$.

[10] 简敏菲,弓晓峰, 游 海. 鄱阳湖流域重金属污染对湖区湿地生态功能的影响及防治对策. 江西科学, 2003,21 (3):230 - 234.

[11] 吕兰军. 鄱阳湖水及其沉积物中的重金属调查. 上海环境科学, 1994,13(5): $17-21$.

[12] 许木启. 利用浮游动物群落结构与功能特征监测乐安江 - 鄱阳湖口重金属污染. 应用与环境生物学 报,1996,2(2):169-174.

[13] 王 嵘,万金保. 乐安河水环境现状调查与保护对策. 江西化工, 2004,3:132-135.

[14] 国家环境保护局. 地面水环境质量标准. 北京: 中国标准出版社, 1988:1-2.

[15] 杨端和. 语言研究应用 SPSS 软件实例大全. 北京: 中国社会科学出版社, 2004:196-242. 